student" is not the one for whom both my patients and I are so grateful. A consultant responsible for a clinical service must accept a major responsibility for the calibre of his team and for delegation of duties to its members. He should learn as well as teach, and I am grateful for all that social workers have taught me concerning the diffculties and at times tragedies complicating the lives of patients. This information has proved vitally important in the planning of treatment and postoperative care.-I am, etc.,

Maternity Department,

John Radcliffe Hospital

SIR,-We ought to be grateful to Mrs. Carole R. Smith for her honest account of the aspirations of hospital social workers (25 August, o. 443) because it should stimulate doctors to define clearly and categorically exactly what is reouired in the hospital service from this group of ancillary workers.

She states that social workers complain that "the most common referrals were for convalescence, home helos, meals on wheels, home nursing or health supervision by health visitors," tasks which, they assert, could readily be done by clerks, whereas the modern social worker with a degree in sociology or psychology should, in thei opinion, fulfil a auite different function This, according to Mrs. Smith, should in clude panticular orientation to the psychosocial functioning of their patients because, she says "she is trained to look for and interpret various cues sent out from the patient, whether they be verbal or nonverbal, and to respond to these in an appropriate way."

It would be interesting to know what special skill the social workers feel they possess which makes them so much bette than doctors or nurses in recognizing and coping with the psychological problem which beset all seriously ill Datients. A skil in such matters certainly cannot be learnt from attending a university course in sociology or psychology because it depends for the most part on inborn intuition and in sight combined with a genuine interest in people, aualities of mind, I humbly submit, as likely to be found in doctors and nurse as in social workers. Further, she states that social workers can be of help to nurses who at times penalize difficult patients without stcpping to inauire why they are difficult. This may on occasions be true, but it is a problem to be solved by the nursing profession and certainly does not call for socia workers to act as interpreters in the nurse patient relationship.

I believe the dissatisfaction felt by hospital social workers is partly the fault of doc tors, who have not laid down sufficiently clear guide-lines as to what is required from them. All other groups of ancillary workers such as physiotherapists, radiographers, and dietitians, have come into being in order to perform well-defined tasks and doctors have devised training specifically for their needs. In contrast to this, the graduate socia worker's course in sociology or psychology is really nothing more than an extension of her general education and does not by itself necessarily fit her for a special role in the hospital team.
Doctors certainly realize the very impor tant place of social workers in the hospitals in organizing and co-ordinating social services for their patients, and it is a matte for sincere regret if the modern graduate feels that such work is beneath her and the possession of a degree makes her wish to intrude into the delicate interpersonal relationships between doctor, ward sister, and patient, when in fact she has no special skills offer in this field.

It should therefore clearly be stated that if Mrs. Smith and other social workers assure us that the organization of essential social services in hospitals can be com petently done by clerks, then we should forthwith stop employing relatively expensive graduate social workers because there is no doubt that in the field of psyshosocial work they are certainly not essential experts in the general wards (that is, non-psychiatric) and with an attitude of mind as revealed by Mrs. Smith they can be considered only to be misplaced intruders. - I am, etc.,

Ashford Hospital,

P. E. BALDRY

\section{Immediate Sterility after Vasectomy}

SIR,-There must be misgivings about the recommendations in Mr. D. Urquhart-Hay's paper (18 August, p. 378).

Nobody can be certain that the nonmotility of sperms seen under the micro scope means that they are dead or, if dead, that they were so at the time of ejaculation. Of the 110 specimens reported on by $\mathrm{Mr}$ Urquhart-Hay, none was completely aspermic. "Few and non-motile" was the best result achieved after 158 days. For safety this is not good enough. If sperms persist at all there must be a leak, and leakage means live sperms. In the view of most of us jealous for the reputation of vasectomy as an efficient method of birth control the double completely negative coun should be insisted on before the patient is given the all-clear.-I am, etc.,

L. N. JACKSON Hon. Director

Crediton, Devon The Crediton Project

\section{Tetracyclines and Young Children}

SIR,-Mr. D. S. Stewart (11 August, p. 320) has again drawn attention to one of the undesirable side effects of prescribing tetracyclines for small children and has noted the evidence suggesting a "modest decline" in the use of this group of drugs. It is thus encouraging to be able to state that, in two parallel studies of genera practice prescribing in the north-east of Scotland, the use of tetracycline at consulta tions for new episodes of respiratory illness by 42 doctors who took part in both studies fell from 127 out of $930(13.6 \%)$ in 1969-70 to 17 out of $1,546(1 \%)$ in 1971-2.

While this change is apparently part of general trend (the extent of which official sources might be able to measure) it is tempting to look for an explanation for this particularly dramatic local change. The fall has in fact coincided with the use of graphs showing consensus opinion among loca general practitioners against the use of tetra- cycline for children at a number of meetings throughout the region, and the major changes in prescribing patterns have been in doctors who were originally "behaving" outside the consensus zone. Similar changes have been noted in the reduction of the use of tetracycline as a primary treatment of tonsillitis at any age (45 out of 501 or $9 \%$ in 1969-70 reducing to 19 out of 661 or $2.9 \%$ in 1971-2) and in both these areas of prescribing in small number of trainee general practitioners. ${ }^{2}$

Worthen ${ }^{3}$ comments on the "legitimizing" effect of peer groups on prescribing habits, and the findings reported above may be a demonstration of how this phenomenon can be put to an educational use. While it is, of course, naive to assume that peer group or consensus opinion is automatically correct (almost, in fact, as naive as ignoring it when it is inconvenient) it appears that in this case we are all broadly in agreement. Mr. Stewart appears unlikely to meet any substantial opposition to his conclusions and recommendations on abstaining from the use of tetracycline in the young.-I am, etc.

J. G. R. HowIE

University Department of General Practice, berdeen

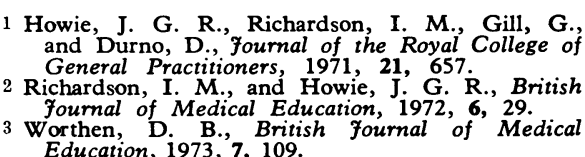

\section{St. John Ambulance Air Wing}

SIR,-With reference to Dr. Z. M. Sharnagiel's letter (1 September, p. 502) concerning the St. John Ambulance Air Wing, the direct telephone number of the flight control centre is Epping 5624. The telephone number given in Dr. Sharnagiel's letter is that of St. Margaret's Hospital, where the centre is based. When the centre is left unattended a recorded message gives the telephone number of the duty flight controller when the above number is dialled. A 24-hour service is maintained by volunteer flight controllers.

The air wing was formed in early 1972 to provide a volunteer air service for the rapid transport of organs, drugs, blood supplies, and patients in emergencies when other means are not available. The function of the air wing is to assist by any possible means in life-saving or emergency missions in the United Kingdom or abroad within the scope and ideals of St. John Ambulance Association.

There are now over 100 pilots with more than 60 single- and twin-engined aircraft. The majority of pilots are formed into groups covering the whole of the U.K. and are able to fly to and from small airfields and landing strips as well as the major airfields. The air wing can usually have an aircraft in the air one hour after the initial call to the flight control centre, and special landing facilities have been made available through co-operation with the R.A.F., R.N. and United States Air Force in the U.K.

To date the air wing has carried out 72 flights, the majority of these for the carriage of transplant kidneys at night. Recently there has been a demand to carry patients, and the air wing has supplied medical and nursing air attendants and medical equip- 
ment on such flights. In addition to the the need for education for childbirth.-We U.K., many flights have been undertaken to are, etc.,

Europe, to such places as Copenhagen, Paris, and Majorca. At the present time the air wing is limited to sitting cases in its own aircraft and chanters air ambulances for stretcher cases. It is hoped that an aircraft may be made available to us in the future for the carriage of stretcher cases. If any of your readers are able to help us in this respect it will enable us to reduce the cost to the patient even further.

All pilots, controllers, and medical and nursing air attendants give their time free, the only expense involved being the running cost of the aircraft and odd items such as landing fees. We shall be pleased to supply further information to any interested readers. - I am, etc.,

D. H. ClaRk

St. John Air Wing,

St. Margaret's Hospital,
Epping, Essex

\section{Active Management of Labour}

SIR,-Recent letters on this subject (11 August, p. 352, and 25 August, p. 453) have given us no reason to alter the opinion that pain in labour is an emotive subject.

In our paper (21 July, p. 135) we sought to emohasize that the problem of pain in labour should not be considered in isolation; we did not dispute that labour is often painful or that epidural block provides a highly effective method of pain relief, and we further recognize that it may not have been sufficiently utilized in our patients. This is, however, a far cry from the suggestion by Professor Selwyn Crawford (25 August, p. 453) that epidural anaesthesia should be recommended to all patients, even to multigravidae before labour has started.

When the results of epidural anaesthesia in labour are evaluated the total welfare of mother and child must be considered and this must at least include an explicit account of perinatal deaths, necropsy examinations, and cases of possible brain damage. To take one important example, between 1963 and 1970 there were 17 perinatal deaths from traumatic intracranial haemorrhage, proved at necropsy, among first-born infants with cephalic presentations in this hospital. Fifteen were delivered with forceps. The incidence of fatal head injury was almost 100 times as high in infants delivered by forceps. Even the most enthusiastic supporters of epidural anaesthesia concede a high incidence of forceps, particularly in primigravidae, and the implications of this for both mother and child have not received nearly enough attention.

The responsibility for mother and child in labour rests with the obstetrician, and the problem of pain is only one, albeit important, aspect of his care in which safety must take precedence above all else. The place of epidural anaesthesia in first labours is not yet clear, but it can be evaluated only in a situation where the management of labour is under strict control and all other important factors are taken into account. We are presently engaged in an attempt at objective assessment of this and the results will be published in due course.

In conclusion we regret Professor Crawford's reference to Grantly Dick Read, who did so much to advance our appreciation of
KIERAN O'DRISCOLL JOHN M. STRONGE

National Maternity Hospital,
Dublin

\section{Irradiation of C.N.S. in Leukaemia}

SIR,-I feel that I must take issue with the arbitrary way in which Dr. D. G. McGowan (21 July, p. 170) has selected certain figures from the St. Tude (Memphis) Total VI study in order to question the early results of the Medical Research Council study (19 May, p. 381) and the value of prophylactic treatment of the central nervous system in childhood leukaemia in general. I am sure there will be commen from the writers of the M.R.C. report, and I will therefore restrict mine to the data he has culled from the St. Jude Total VI study.

In questioning the effects of this treatment on survival Dr. MaGowan ignores the fact that the St. Jude group has repeatedly stressed, and elegantly demonstrated ${ }^{1}$ that early survival figures (that is, about four years from the start of the trial from which he quotes) are misleading. With curren therapy it is possible to keep many patient alive for prolonged periods through several relapses, even though they will eventually die. Patients who relapse after adequate treatment have infrequently become longterm survivors. Since "we are now thinking in terms of cure," to quote his own words, he should use the continuous complete remission rate, which is the quickest and most reliable index of long-term leukaemia-free survival. The figures of $30 / 45(66 \%)$ survivors in the prophylactic treatment group and $29 / 49(60 \%)$ in the non-prophylactic group which he quotes are very misleading when compared with the published continuous complete remission rates of 29/45 $(64 \%)$ and $11 / 49(22 \%)$ respectively for the holds true for the haematological relapse rates referred to in his second question

When Dr. McGowan turns to the effects of C.N.S. prophylaxis on C.N.S. leukaemia in the same study he quotes figures of $3 / 45$ $(6.7 \%)$ of patients in the prophylactic treatment group subsequently developing C.N.S. leukaemia. He then compares this with figures from a much earlier report for the non-prophylactic group of $5 / 47 \quad(10.6 \%)$ treated for C.N.S. disease who had subsequently had C.N.S. recurrence (two patient excluded who were actually receiving radiation for C.N.S. disease). The data published by the St. Jude group ${ }^{1}$ show that at a time when $2 / 45(4.4 \%)$ of the prophylactically treated group had developed C.N.S. disease, 46 months from the onset of the study, $32 / 49(65.3 \%)$ of the non-prophylactic group had developed C.N.S. disease, and only 15 of the 32 C.N.S.-relapsed patients remained in a second complete remission, $9 / 17(>50 \%)$ second relapses having involved the C.N.S. despite therapeutic radiation. Even if these figures did not speak so eloquently for themselves, it is surely statistical nonsense to comoare the percenlactic radiation early with those given therapeutic radiation much later without taking account of the very substantial difference in time at risk of developing same groups of patients. ${ }^{1}$ The same argument tage of relapses in one group given prophy-
C.N.S. disease subsequent to radiation in the two groups.

Finally, there is the question of the potential hazards of C.N.S. radiation. These are, of course, a matter of considerable concern and debate, and no doubt we will all be relieved when someone finds an effective and less potentially toxic form of prophylactic treatment, or an effective form of therapeutic treatment, so that the $20 \%$ of patients who will not develop C.N.S. disease in the long term may be spared unnecessary treatment. As things stand at present, however, prophylactic C.N.S. radiation has revolutionized the treatment of childhood acute lymphoblastic leukaemia and provided the prospect of eradication of the disease in the majority of cases. It will require strong grounds indeed to justify ethically the withholding of this treatment from the current generation of patients, even if some of them do develop the potential complications mentioned, until an effective substitute has been found.-I am, etc.,

M. G. Motr

University Department of Child Health,

Royal Hospital for Sick Children, Bristol

Simone, J., Aur, R. J. A., Hustu, H. A., and

Economics of Varicose Veins

SIR,-In your leading article (16 June, p. 626) you state that "because sclerotherapy can be undertaken on an outpatient basis, patients usually prefer it to surgical treatment. It is an economic help to them, for they can continue with normal activities while under treatment. Another advantage is that pressure on expensive bed and theatre time is reduced."

As a result of experience with more than 4,000 stripping operations for varicose veins the length of hospital stay has been decreased so that stripping procedures can now be performed on a fully ambulatory basis. Five hundred patients have been operated upon on an ambulatory basis. ${ }^{1}$ The patient is admitted to the hospital at 7.30 a.m. and discharged between 2 and 5 p.m. The operation is performed under a light general anaesthesia. The ambulatory technique minimizes postoperative morbidity. The patient is instructed to work and carry out all usual activities the day following surgery. With this technique there has been a great saving of hospital beds and work-hours lost to industry. Even before the ambulatory technique was started, about 3,500 patients were operated upon on a semi-ambulatory basis. The patient was admitted to the hospital the evening before surgery. Operation was performed the next morning and the patient discharged the same day or the following morning at the latest. An elastic support is necessary for 10-14 days following surgery, whereas with the injection-compression technique the bandage is used for much longer periods. Following operation, only abour two postoperative visits are necessary for suture removal or possible injections for residual varices.

Since surgery can now be performed on an ambulatory basis, it is especially importan to disregard economic factors and concentrate on specific indications. With marked valvular insufficiency and large varices ligation and stripping is more effective. Injection 